Article

\title{
Perceptions, Attitudes, and Barriers to Obesity Management in Spain: Results from the Spanish Cohort of the International ACTION-IO Observation Study
}

\author{
Javier Salvador ${ }^{1,2, *} \mathbb{C}$, Nuria Vilarrasa ${ }^{3,4}\left(\mathbb{D}\right.$, Francisco Poyato ${ }^{5}$ and Miguel Ángel Rubio ${ }^{6,7}$ \\ 1 Department of Endocrinology and Nutrition, University Clinic of Navarra, 31008 Pamplona, Spain \\ 2 CIBER Physiopathology of Obesity and Nutrition (CIBERobn), 28029 Madrid, Spain \\ 3 Department of Endocrinology, Diabetes and Nutrition, Bellvitge University Hospital-IDIBELL, \\ L'Hospitalet de Llobregat, 08907 Barcelona, Spain; nuriavilarrasa@yahoo.es \\ 4 CIBER Diabetes and Associated Metabolic Diseases (CIBERDEM), 28029 Madrid, Spain \\ 5 Obesity Medical Department, Novo Nordisk Spain, 28033 Madrid, Spain; fpca@novonordisk.com \\ 6 Department of Endocrinology and Nutrition, San Carlos Clinical Hospital and Health Research Institute of \\ the San Carlos Clinical Hospital (IdISSC), 28040 Madrid, Spain; marubioh@gmail.com \\ 7 Faculty of Medicine, Complutense University of Madrid, 28040 Madrid, Spain \\ * Correspondence: jsalvador@unav.es; Tel.: +34-948255400 (ext. 4481)
}

Received: 13 July 2020; Accepted: 27 August 2020; Published: 2 September 2020

\begin{abstract}
The prevalence of obesity is rapidly rising in Spain. The Awareness, Care and Treatment in Obesity Management-An International Observation (ACTION-IO) study (NCT03584191) was an international cross-sectional survey conducted to identify the perceptions, attitudes, behaviors, and barriers to obesity management for people with obesity $(\mathrm{PwO})$ and healthcare professionals (HCPs); results from Spain are presented. In Spain, $1500 \mathrm{PwO}$ (body mass index $\geq 30 \mathrm{~kg} / \mathrm{m}^{2}$ based on self-reported height and weight) and $306 \mathrm{HCPs}$ (in direct patient care for $\geq 2$ years) completed the survey. Fewer $\mathrm{PwO}(59 \%)$ than HCPs (93\%) agreed that obesity is a chronic disease. Most PwO $(80 \%)$ assumed complete responsibility for their own weight loss, whilst $19 \%$ of HCPs placed the responsibility on PwO. One-fifth of $\mathrm{PwO}$ stated they began struggling with weight before age 15 . The mean delay in discussing weight for the first time with an HCP was 6 years. Only $24 \%$ of HCPs thought their patients were motivated to lose weight, whilst $45 \%$ of $\mathrm{PwO}$ reported being motivated. Of the $67 \%$ of PwO who had discussed their weight with an HCP in the last 5 years, $66 \%$ had been formally diagnosed with obesity. Our Spanish dataset reveals discrepancies in the perceptions and attitudes between $\mathrm{PwO}$ and HCPs, thus highlighting the need to improve education about obesity and its clinical management.
\end{abstract}

Keywords: obesity; weight loss; ACTION-IO; perceptions; barriers; obesity management; Spain

\section{Introduction}

The current obesity pandemic is among the main challenges for public health due to its impact on early morbidity and mortality and linked associated comorbidities [1,2]. Excessive adipose tissue, particularly visceral and ectopic fat, represent independent predictive factors of major acute cardiovascular events and mortality [3]. In addition, obesity reduces the patient quality of life and is a major burden on healthcare and healthcare system expenses [4]. Most recently, obesity has also been identified as a potential key risk factor for susceptibility to COVID-19 [5,6].

The prevalence of obesity in Spain is $22.9 \%$ and $39.4 \%$ of individuals are considered overweight [7], with an upward trend predicted in the coming years, as seen in other Western countries [8]. In fact, 
if the current trend continues in Spain, it has been estimated that the number of patients with excess weight will increase by $16 \%$ by 2030 , leading to 3.1 billion EUR per year of extra direct medical costs [9].

Obesity is a complex, chronic disease with a multifactorial etiology; genetic, epigenetic, physiological, behavioral, socio-cultural, and environmental factors all contribute to the imbalance in energy homeostasis that leads to obesity [10-12]. Guidelines defined by different scientific societies are currently available to help effectively address the diagnosis and treatment of obesity [13-15]. However, healthcare professional (HCP) familiarity with these guidelines and knowledge of evidence-based clinical management of obesity is reportedly low $[16,17]$. Furthermore, people with obesity $(\mathrm{PwO})$ are often subject to stigma and discrimination in both social and healthcare settings $[18,19]$. Discrimination and stigma (including self-directed stigma whereby $\mathrm{PwO}$ blame themselves) is associated with poor mental health, poor quality of life, unhealthy eating, and avoidance of exercise among others [19-21]. Obesity stigma can exist among HCPs, which poses barriers to the diagnostic and therapeutic approach to this condition [18], and is associated with poor treatment outcomes for $\mathrm{PwO}$ [19]. Evidence suggests that a lack of education regarding the complex etiology of obesity contributes to obesity stigma [19]. Due to the public health threat that obesity stigma poses, guidelines and an international consensus of experts have called for ending obesity stigma via increased education and better communication between HCPs and $\mathrm{PwO}$ in order to address the barriers to diagnosis and treatment $[15,18,19]$.

The Awareness, Care and Treatment In Obesity maNagement (ACTION) studies were designed to identify the perceptions, attitudes, behaviors, and potential barriers to obesity management for PwO and HCPs. The results may provide an awareness of the real problem and the difficulties encountered by both groups in the approach and control of obesity. Results are currently available from the ACTION US [22], ACTION Canada [23], and ACTION-An International Observation (ACTION-IO) [24] studies, with Spain participating in ACTION-IO. The main objective of this paper is to present the results obtained from the Spanish population, highlighting the similarities and differences with respect to the global results from all participating countries, in order to establish specific strategies to optimize the treatment of obesity in Spain.

\section{Methods}

\subsection{Study Design and Participants}

The methodology for the ACTION-IO study has been reported previously [24]. In summary, it was a cross-sectional, non-interventional, descriptive study that collected data via an online survey of $\mathrm{PwO}$ and HCPs conducted in 11 countries: Australia, Chile, Israel, Italy, Japan, Mexico, Saudi Arabia, South Korea, Spain, the United Arab Emirates (UAE), and the United Kingdom (UK). Spanish participants completed the survey between July 27, 2018 and September 6, 2018.

The study was designed by an international steering committee of obesity experts, representing primary care, medical specialties, and psychology, and three medical doctors employed by Novo Nordisk. The survey was based on those used in the ACTION US [22] and ACTION Canada [23] studies. To avoid response bias, questionnaire items were carefully phrased and presented in the same order and the listed items were shown in alphabetical, categorical, chronological or random order, as relevant for each response set, the full text of the questionnaires has been previously published [24]. A third-party vendor (KJT Group (Honeoye Falls, NY, USA)) conducted the online survey and managed the data collection and analysis. In Spain, the study questionnaires were approved by the Research Ethical Committee of the University of Navarra (Pamplona, Spain). All procedures in this study complied with the laws and regulations regarding the management of personal information as required by Spain and the European General Data Protection Regulation. The study was sponsored by Novo Nordisk, conducted in accordance with the Guidelines for Good Pharmacoepidemiology Practices [25] and the Declaration of Helsinki [26], and is registered with ClinicalTrials.gov (NCT03584191). 
Eligible PwO were aged 18 years or older, with a current body mass index (BMI), based on self-reported height and weight, of at least $30 \mathrm{~kg} / \mathrm{m}^{2}$. Exclusion criteria included pregnancy, participation in intense fitness or body building programs, or significant, unintentional weight loss during the past 6 months. Eligible HCPs were medical practitioners who had been in practice for 2 years or more, with at least $50 \%$ of their time involved in direct patient care and who had seen 100 or more patients during the past month, at least ten of whom had a BMI of at least $30 \mathrm{~kg} / \mathrm{m}^{2}$. HCPs specializing in general, plastic, or bariatric surgery were excluded. All respondents provided electronic informed consent prior to initiation of the screening questions and survey.

Respondents were mostly recruited via online panel companies to whom they had given permission to be contacted for research purposes. Spanish respondents were recruited via email and were offered the survey in Spanish or English. To minimize the sampling bias, PwO data were stratified, whereby the outbound sample was sent according to pre-determined demographic targets based on age, gender, household income, education, and region. Targets were established based on data from the Organization for Economic Co-operation and Development (Labour Force Survey, 2018) and the US Census Bureau, International Data Base, and were monitored throughout the data collection to ensure population representativeness. Prior to participation, $\mathrm{PwO}$ were blinded to the specific study goals, being informed that the purpose was "to determine the treatment experiences of patients with a specific condition". Screening questions were used to determine eligibility based on these demographic targets. Respondents who passed the screening process, had a BMI of at least $30 \mathrm{~kg} / \mathrm{m}^{2}$, and who met the other study eligibility criteria, were permitted to complete the full survey.

Sample sizes were calculated based on the usual acceptance of a smallest sub-sample $(n \sim 50)$, previous experience with the ACTION US and ACTION Canada studies, and the intention to conduct country-specific sub-analyses. Response rates for the international ACTION-IO study were expected to be $\sim 9.7 \%$ for PwO and $\sim 20.4 \%$ for HCPs, based on what was seen in ACTION US. A statistical analysis was not conducted to determine the sample size, but rather market knowledge, previous market research experience, published data on the prevalence of obesity in Spain, and total population estimates were utilized to determine the sample feasibility and requirement. Given these inputs, a sample of size 1500 for PwO and 300 for HCPs was determined optimal. Additional PwO sample size considerations for the Spanish cohort of the ACTION-IO study are presented in Table 1.

Table 1. Sample size considerations for the Spanish cohort of the Awareness, Care and Treatment in Obesity Management-An International Observation (ACTION-IO) study.

\begin{tabular}{ccccccc}
\hline Country & $\begin{array}{c}\text { Prevalence } \\
\text { of Obesity * }\end{array}$ & $\begin{array}{c}\text { Total } \\
\text { Population } \\
\text { Estimates }\end{array}$ & $\begin{array}{c}\text { Estimated } \\
\text { Number of } \\
\text { PwO }\end{array}$ & $\begin{array}{c}\text { PwO Sample Size } \\
\text { Recommendation }\end{array}$ & $\begin{array}{c}\text { Sample Size of } \\
\text { Population with } \\
\text { Obesity }\end{array}$ & $\begin{array}{c}\text { Margin of } \\
\text { Error }^{+}\end{array}$ \\
\hline Spain & $24 \%$ & $47,400,000$ & $11,376,000$ & 1500 & $0.013 \%$ & $2.5 \%$ \\
\hline
\end{tabular}

$\mathrm{PwO}$, people with obesity. * Body mass index $(\mathrm{BMI}) \geq 30 \mathrm{~kg} / \mathrm{m}^{2} .{ }^{\dagger} \mathrm{PwO}$ estimations based on the prevalence of obesity (22.9\%) in the Spanish adult population, as reported by the Estudio de Nutrición y RIesgo CArdiovascular en España (ENRICA) study [7], fall within this margin of error.

\subsection{Statistical Analysis}

The analysis of de-identified data was performed by the KJT Group using SPSS (IBM, version 23.0), Stata (StataCorp LLC, version IC 14.2), and Excel (Microsoft, version 2016). Results were presented using descriptive statistics (means, medians, frequencies). The final PwO sample, which satisfied the representative demographic targets (age, gender, household income, education, and region), was weighted. The HCP data were monitored for specialist types but were not weighted. 


\section{Results}

\subsection{Participants}

The ACTION-IO survey was completed by 1500 PwO and 306 HCPs in Spain (Table 2). The response rate was $24 \%$ for $\mathrm{PwO}$ and $6 \%$ for HCPs, with final eligibility rates of $11 \%$ and $55 \%$ for each group, respectively. Approximately half (52\%) of the $\mathrm{PwO}$ were female and the majority had a BMI classification of Class I obesity (BMI 30.0-34.9 kg/m²); the mean age was 45 years. Of the participating Spanish HCPs, almost half were specialists, with $24 \%$ of HCPs specializing in endocrinology.

Table 2. Sample demographics and characteristics.

\begin{tabular}{|c|c|c|}
\hline & PwO $(n=1500)$ & HCPs $(n=306)$ \\
\hline Age, years (range) & $45(18-81)$ & $50(30-69)$ \\
\hline \multicolumn{3}{|l|}{ Gender, $n(\%)$} \\
\hline Female & $776(52)$ & $218(71)$ \\
\hline Male & $721(48)$ & $88(29)$ \\
\hline Other & $3(<1)$ & 0 \\
\hline \multicolumn{3}{|c|}{ BMI classification, $n(\%)$} \\
\hline Respondents & $1500(100)$ & $264(86)$ \\
\hline Underweight or healthy range $\left(<25 \mathrm{~kg} / \mathrm{m}^{2}\right)$ & - & $150(57)$ \\
\hline Overweight $\left(25-29.9 \mathrm{~kg} / \mathrm{m}^{2}\right)$ & - & $107(41)$ \\
\hline Obesity Class I (30-34.9 kg/m²) & $1029(69)$ & $6(2)$ \\
\hline Obesity Class II $(35-39.9$ kg/m²) & $282(18)$ & 0 \\
\hline Obesity Class III $\left(\geq 40 \mathrm{~kg} / \mathrm{m}^{2}\right)$ & $189(12)$ & $1(<1)$ \\
\hline \multicolumn{3}{|c|}{ Number of comorbidities, $n(\%)$} \\
\hline 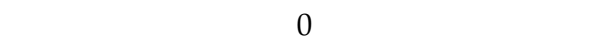 & $326(17)$ & - \\
\hline 1 & $370(21)$ & - \\
\hline 2 & $335(24)$ & - \\
\hline 3 & $242(19)$ & - \\
\hline$\geq 4$ & $227(19)$ & - \\
\hline \multicolumn{3}{|c|}{ HCP category, $n(\%)$} \\
\hline PCP & - & $156(51)$ \\
\hline Specialist & - & $150(49)$ \\
\hline Endocrinologist & - & $73(24)$ \\
\hline Internal medicine (non-PCP) & - & $23(8)$ \\
\hline Other * & - & $54(18)$ \\
\hline \multicolumn{3}{|c|}{ Obesity specialist, $n(\%)^{\dagger}$} \\
\hline Yes & - & $247(81)$ \\
\hline No & - & $59(19)$ \\
\hline
\end{tabular}

All PwO N numbers and percentages for demographic results (age, gender) are from unweighted data, whereas the $\mathrm{PwO}$ percentages for non-demographic results are weighted. HCP data were not weighted, therefore, all HCP N numbers and percentages are from unweighted data. * includes HCPs who self-reported their specialty as 'other.' ${ }^{+}$indicates a physician who meets at least one of the following criteria: at least $50 \%$ of their patients are seen for obesity/weight management; has advanced/formal training in the treatment of obesity/weight management beyond medical school; considers themselves to be an expert in obesity/weight loss management; or works in an obesity service clinic. BMI, body mass index; HCP, healthcare professional; PwO, people with obesity; PCP, primary care physician.

\subsection{Perception of Obesity as a Chronic Disease}

A total of $93 \%$ of HCPs considered obesity to be a chronic disease. Despite $83 \%$ of PwO reporting one or more comorbidities, only 59\% considered obesity to be a chronic disease. Most PwO (80\%) and HCPs $(86 \%)$ considered obesity to have a large impact on overall health, like other chronic diseases, such as stroke, diabetes, cancer, or chronic obstructive pulmonary disease (Supplementary Figure S1). However, PwO tended to underestimate their own weight status: $73 \%$ considered themselves as having either normal weight or being overweight, while the remaining PwO perceived themselves as having obesity ( $24 \%$ ) or extreme obesity ( $2 \%)$. 


\subsection{Responsibility and Motivation for Treating Obesity}

The majority of $\mathrm{PwO}(80 \%)$ assumed complete responsibility for their own weight loss and $68 \%$ believed they could lose weight if they tried (Figure 1). Conversely, only 19\% of HCPs considered weight loss to be the sole responsibility of their patients with obesity; most HCPs (83\%) also considered their patient's weight loss to be a responsibility of their professional practice. Only $24 \%$ of HCPs believed that their patients were motivated to lose weight, in contrast with the $45 \%$ of $\mathrm{PwO}$ who stated that they were, in fact, motivated to lose weight. Both $\mathrm{PwO}$ and $\mathrm{HCPs}$ perceived unhealthy eating habits (56\% of $\mathrm{PwO} ; 90 \%$ of $\mathrm{HCPs}$ ) and lack of physical activity (70\% of $\mathrm{PwO} ; 90 \%$ of $\mathrm{HCPs}$ ) as barriers for weight loss, whereas fewer than half ( $39 \%$ of $\mathrm{PwO} ; 42 \%$ of $\mathrm{HCPs}$ ) considered genetic factors to be an obstacle.

\section{Attitudes towards obesity}

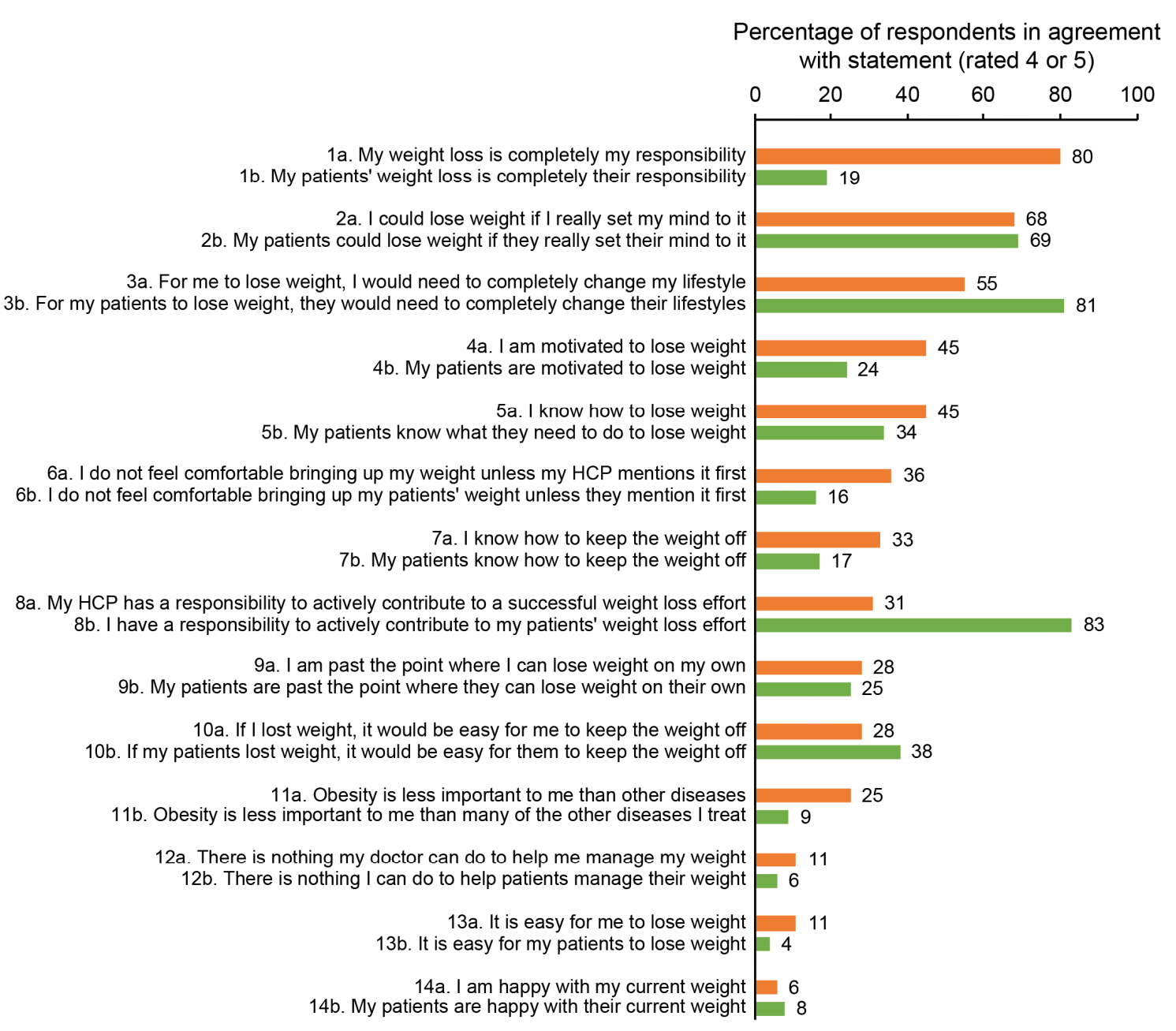

- PwO, $n=1500$; $\square \mathrm{HCPs}, n=306$; in response to $\mathrm{Q} 500 / 503$

Figure 1. $\mathrm{PwO}$ and $\mathrm{HCP}$ agreement with statements regarding attitudes towards obesity. $\mathrm{PwO}=$ orange; $\mathrm{HCPs}=$ green. $\mathrm{HCP}$, healthcare professional; $\mathrm{PwO}$, people with obesity. Rated on a scale of 1-5.

\subsection{Previous Weight Loss Attempts and Outcomes}

Most PwO reported having made at least one serious attempt at weight loss (mean: four attempts) (Figure 2a); however, only $13 \%$ of $\mathrm{PwO}$ were able to maintain a weight loss of $\geq 5 \%$ for at least one year (Figure 2b). 
(a) Number of past serious weight loss attempts

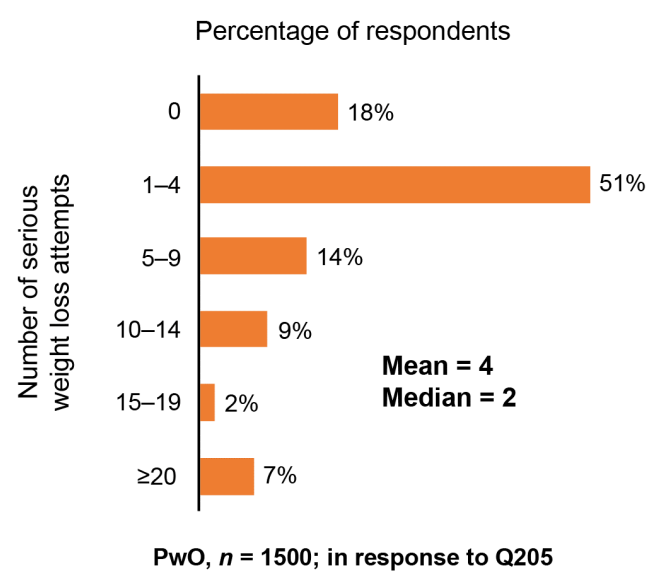

(b) Extent and maintenance of weight loss in last 3 years at threshold of $\mathbf{5 \%}$

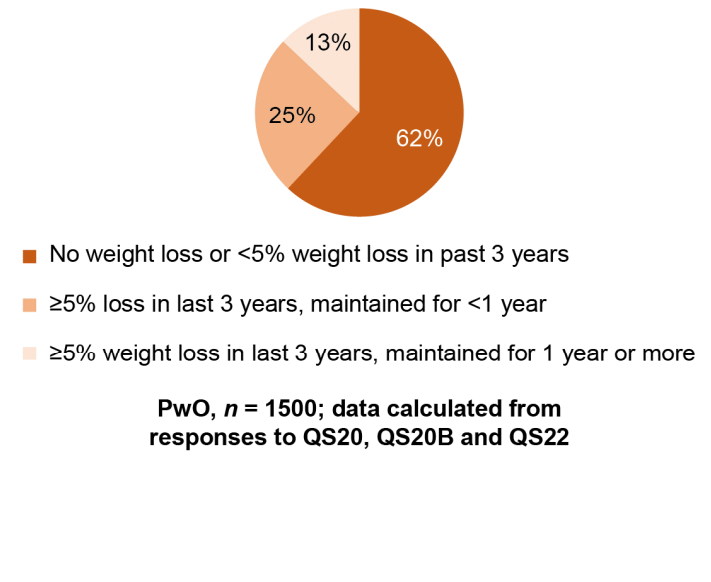

Figure 2. Weight loss efforts and maintenance. (a) Number of serious past weight loss attempts by $\mathrm{PwO}$; (b) PwO extent and maintenance of weight loss in the last 3 years at a threshold of $5 \%$ of total body weight. PwO, people with obesity.

\subsection{Conversations Between PwO and HCPs}

Only $67 \%$ of all $\mathrm{PwO}$ reported having had a conversation with their $\mathrm{HCP}$ about their weight problem in the past 5 years (Figure 3a). Surprisingly, the mean time interval between the initial concern regarding weight and the first conversation was 6 years (Figure $3 b$ ) and the mean age at the time of the initial consultation was 38 years (Figure 3c). Although the mean age at which PwO began struggling with their weight was 34 years, there was a high percentage of $\mathrm{PwO}$ whose concerns about excess weight began at under 16 years of age (20\%; Figure $3 \mathrm{~d})$.

Overall, most $\mathrm{PwO}(\sim 75 \%)$ expressed a desire for the $\mathrm{HCP}$ to initiate a weight management dialogue. The main reason for the HCPs initiating a dialogue was related to the presence of complications associated with obesity (selected by $71 \%$ of HCPs), followed by the patient's BMI value as a reason for initiating dialogue compared with the global dataset (selected by $65 \%$ of HCPs). The most common reason $(42 \%)$ given by $\mathrm{PwO}$ to not discuss their weight was the conviction that weight loss was entirely their own responsibility (Figure 4 and Supplementary Figure S2). In contrast, for HCPs, it was the perception that the patient is not interested in or not motivated for weight loss (75\% each), which was in clear disagreement with the opinion of the PwO (Figure 4 and Supplementary Figure S2). Additionally, the short duration of time for each patient consultation was another of the relevant causes for the HCP not initiating a dialogue (62\%). 
(a) Proportion of PwO having weight management discussions, obesity diagnoses, and follow-up appointments/calls

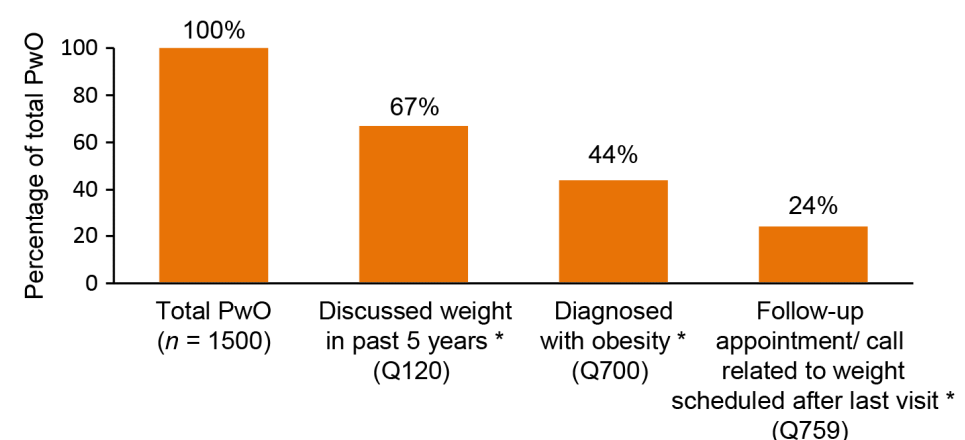

(b) Time between started struggling with weight and had a weight management discussion

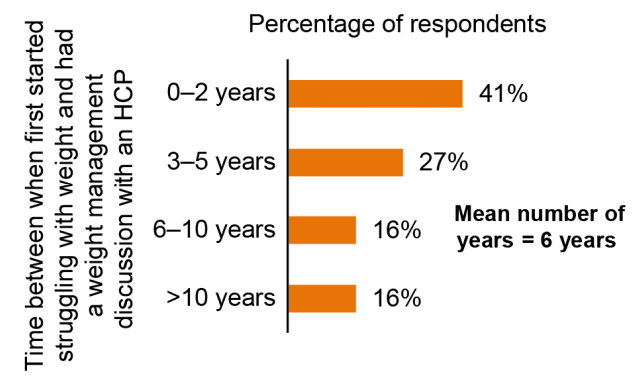

PwO who discussed weight with HCP in the past 5 years; data calculated at respondent level from questions Q122 and Q122A ( $n=1059)$

\section{(d) Age when PwO began struggle with weight}

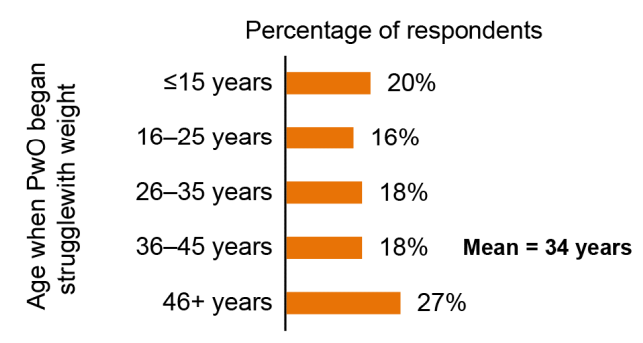

Age when PwO began struggle with weight;

$$
\text { Q122A }(n=1500)
$$

Figure 3. Weight management conversations and outcomes. (a) The proportion of PwO who have had weight management discussions with an HCP, obesity diagnoses, and follow-up appointments/calls; (b) time gap between first struggling with weight and having a weight management discussion with an HCP; (c) the age when PwO first discussed their weight with an HCP; (d) the age when PwO began their struggle with weight. * Percentage results are based on the total number of Spanish PwO $(n=1500)$. HCP, healthcare professional; PwO, people with obesity. 


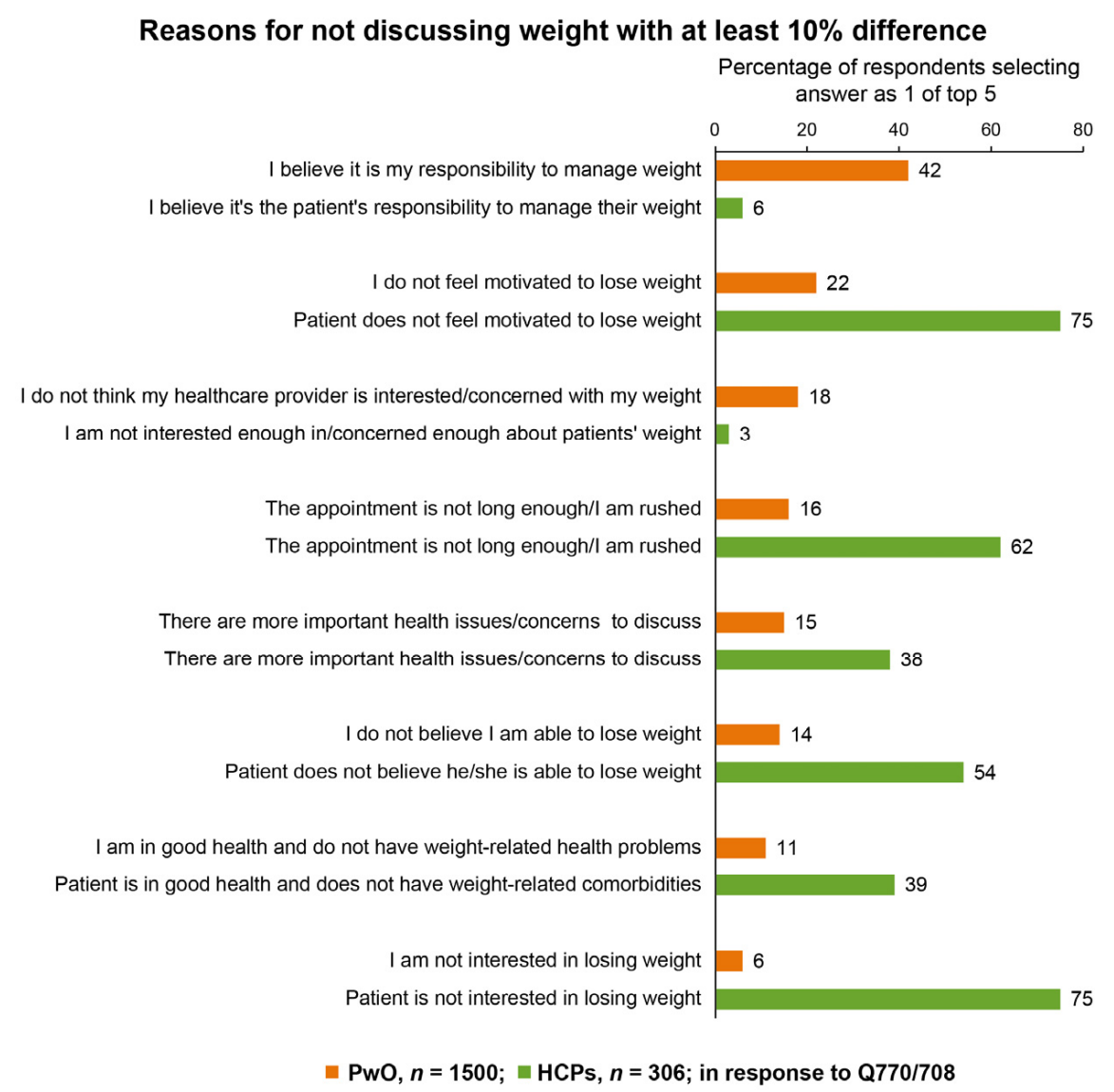

Figure 4. Reasons for not discussing weight with an $\mathrm{HCP}(\mathrm{PwO}$, orange) or patient (HCPs, green) with at least $10 \%$ difference. Respondents selected their top 5 reasons from the list of options. Reasons for not discussing weight with an $\mathrm{HCP}$ or patient with at least $10 \%$ difference between $\mathrm{PwO}$ and HCPs are presented. See Supplementary Figure S2 for all reasons. HCP, healthcare professional; PwO, people with obesity.

\subsection{Treatment Objectives}

Even though $83 \%$ of $\mathrm{PwO}$ consider that a loss of $5-10 \%$ body weight would be beneficial to their health, $50 \%$ of $\mathrm{PwO}$ set themselves a weight reduction goal of $11-20 \%$ (overall average of $14.5 \%$ for all $\mathrm{PwO}$ ). People with obesity reported that the recommendation indicated by their HCP was of a similar magnitude (mean 17\%). For $\mathrm{PwO}$, the weight management goals most frequently selected were to reduce the risk of obesity-related comorbidities $(49 \%)$ and to improve their physical appearance $(36 \%)$; the main motivators for losing weight included wanting to feel better physically (52\%), to be more fit/in better shape (48\%), and to improve general health (36\%). The therapeutic objectives set with HCPs were mainly aimed at improving health (35\%) more than physical appearance $(15 \%)$.

\subsection{Diagnosis of Obesity and Scheduling of Follow-Up Appointments}

Of the $\mathrm{PwO}$ who had discussed excess weight or losing weight with their $\mathrm{HCP}$ in the last 5 years, only $66 \%$ had been formally diagnosed with obesity ( $44 \%$ of $\mathrm{PwO}$ in total), and only $36 \%$ indicated that they had any scheduled follow-up on their progress ( $24 \%$ of $\mathrm{PwO}$ in total; Figure $3 \mathrm{a}$ ). A total of $78 \%$ of those who did not have the conversation would have liked to have had a follow-up appointment scheduled. Primary care physicians were the $\mathrm{HCP}$ that most $\mathrm{PwO}(78 \%)$ had ever discussed their weight with, followed by nurses (30\%) and endocrinologists (29\%). Endocrinologists were the professionals perceived by HCPs as being the most effective at helping $\mathrm{PwO}$ manage their weight. 


\subsection{Perception of Efficacy and Indication of Treatments for Obesity}

Both improvements in eating habits and physical activity were the strategies most commonly mentioned in conversations between $\mathrm{PwO}$ and HCPs (Figure 5a) and were perceived as highly effective weight management strategies by both $\mathrm{PwO}$ and HCPs (Figure 5b). Pharmacologic treatments were perceived to be of low efficacy by both groups. Interestingly, only $32 \%$ of HCPs believed that there are good options available for prescription weight loss medications, and $37 \%$ acknowledged that they did not know enough about prescription weight loss medications to feel comfortable prescribing them to their patients. Bariatric surgery was also considered to be a less effective mid- or long-term treatment alternative; only $39 \%$ of $\mathrm{PwO}$ and $55 \%$ of HCPs believed that bariatric surgery would be more effective than other treatment options for weight loss.

Of the sources of information most commonly used by PwO to manage their weight, the HCP was clearly ranked much higher than other sources of information (used by $46 \%$ of $\mathrm{PwO}$ ), such as the internet $(30 \%)$, friends and family $(27 \%)$, and television programs ( $8 \%$; Supplementary Figure S3).

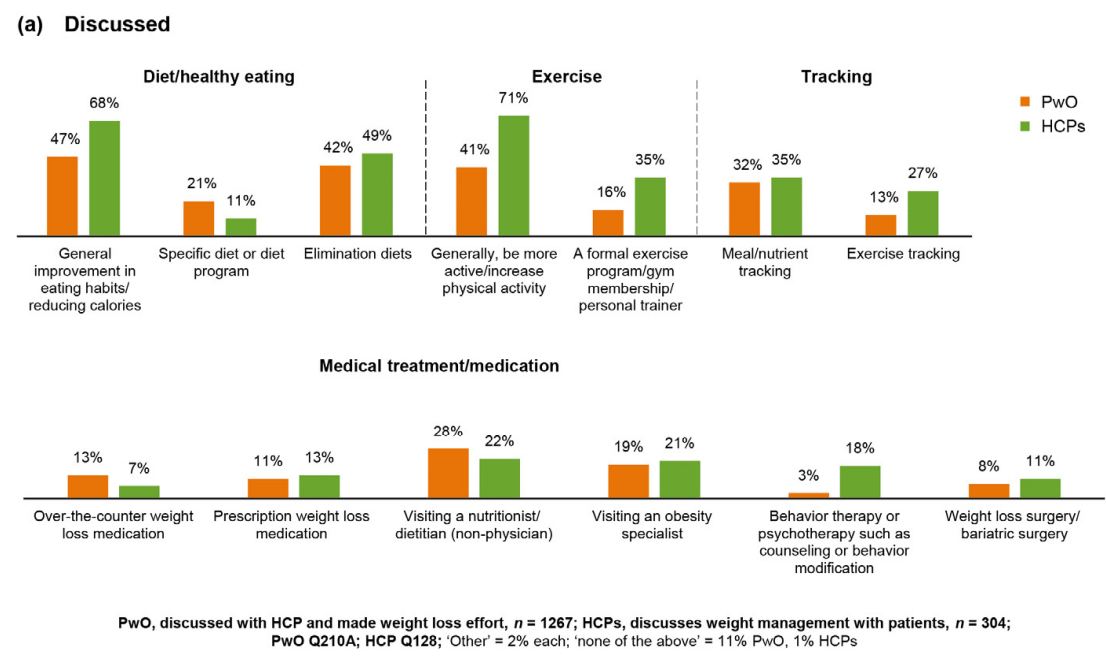

(b) Perceived as effective
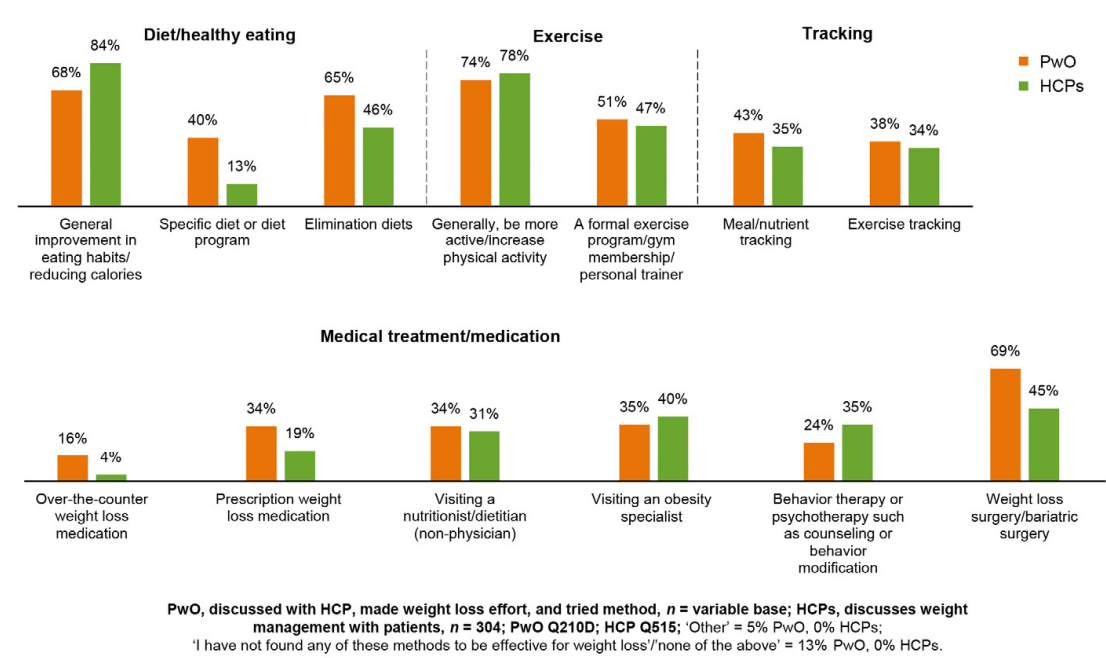

Figure 5. Weight management methods discussed/recommended and perceived effectiveness. (a) Weight management methods discussed with an HCP (reported by PwO) and recommended by HCPs; (b) weight management methods perceived as effective by HCPs or PwO. PwO = orange; $\mathrm{HCPs}=$ green. $\mathrm{HCP}$, healthcare professional; $\mathrm{PwO}$, people with obesity. 


\section{Discussion}

The Spanish results from the ACTION-IO study highlight the discrepancies between the perceptions and attitudes of $\mathrm{PwO}$ and HCPs; these constitute important barriers for the diagnosis and treatment of obesity per the guidelines on obesity management from the different scientific societies $[14,27,28]$.

The study revealed a lack of recognition of obesity as a chronic disease by $\mathrm{PwO}$ in up to $41 \%$ of cases, even though most (83\%) reported comorbidities. This lack of recognition is higher than that seen in the global dataset (32\%) [24], despite fewer $\mathrm{PwO}(74 \%)$ being affected by comorbidities (ACTION-IO study steering committee, personal communication). In addition, only $26 \%$ of $\mathrm{PwO}$ perceived themselves as having obesity or extreme obesity, although all had a BMI of $\geq 30 \mathrm{~kg} / \mathrm{m}^{2}$ (according to self-reported weight and height). This percentage is markedly lower than in the global population (43\%; ACTION-IO study steering committee, personal communication) and from other population-based studies [29], including the National Health and Nutrition Examination Survey [30]. This misperception of body weight may help explain the reduced perception of chronic disease and delayed consultation with HCPs.

In line with the necessary identification of chronic diseases, it is alarming that only $66 \%$ of those $\mathrm{PwO}$ who discussed weight with their HCP received a formal diagnosis of obesity. However, this figure is higher than that observed in ACTION US (55\%) [22] and ACTION Canada (48\%) [23]. The low diagnosis rate could potentially explain the low rate of scheduled follow-ups in Spain (36\%), which is nevertheless higher than those seen in ACTION US (24\%) and ACTION Canada (28\%) [22,23]. Therefore, the medical action taken differs greatly from the treatment provided for other chronic diseases, such as hypertension or diabetes mellitus, that are adequately diagnosed and monitored with the regular scheduling of follow-up appointments [31,32]. The correct diagnosis of obesity could change the perception of weight in $\mathrm{PwO}$, increase engagement with $\mathrm{HCPs}$, and facilitate the scheduling of follow-up appointments, enabling measures to ensure a healthy weight [33].

Among the main barriers found in the ACTION studies was the difficulties in engaging in a conversation between $\mathrm{PwO}$ and HCPs regarding obesity. In Spain, up to one-third of PwO do not discuss this condition with their HCPs, and this is primarily because they consider weight loss to be entirely their own responsibility, in line with previously published studies [22-24]. This is particularly surprising considering that the Spanish public health system provides universal coverage. Among HCPs, the most common reason for not initiating a conversation with their patients was the belief that $\mathrm{PwO}$ are not interested or motivated to lose weight, which differed from what was expressed by $\mathrm{PwO}$ themselves. Time constraints for visits were another one of the main arguments highlighted by HCPs for not initiating the dialogue. Only 19\% of HCPs considered weight loss to be the sole responsibility of their patients with obesity, which is lower than the percentage reported in the global cohort (30\%) [24]. Therefore, the data presented here may encourage HCPs to reflect on this matter and alter their perception that their patients lack motivation. In this regard, other studies have also shown that $\mathrm{PwO}$ are highly motivated, particularly when they are offered the option to participate in an intensive behavior modification program to lose weight, in which case the rate of willingness to participate reaches up to $63 \%$ [34].

The time constraints and perceptions of HCPs could explain the mean delay of 6 years observed between $\mathrm{PwO}$ being concerned about excess weight and the initiation of the first conversation with the $\mathrm{HCP}$, which postpones the start of treatment and contributes to the development of complications. Although the mean age at the time of initial conversation with an HCP was similar in the Spanish and global ACTION-IO cohorts, it should be noted that the onset of this initial concern is more frequently under 16 years of age in Spain (20\%) than in the global population of the ACTION-IO study $(15 \%$; ACTION-IO study steering committee, personal communication). This is probably a reflection of the elevated prevalence of obesity in the Spanish pediatric population, which reaches rates of $18.1 \%$ [35]. 
In this study, the most important objectives of $\mathrm{PwO}$ for losing weight were to reduce the risks associated with obesity to prevent disease, and, to a lesser extent, to improve physical appearance. Regarding the approach to therapeutic objectives, one relevant finding of the ACTION-IO study that was also observed in the Spanish data was that the weight loss goals of $\mathrm{PwO}$ are unrealistic, being set at losing $15 \%$ of their body weight. This figure differs from the current recommendations, which place a reduction of $5-10 \%$ as a realistic, achievable goal, which also leads to a significant decrease in the classic cardiovascular risk factors $[13,36]$. The desire to lose two to three times more weight than realistic goals has previously been described in other populations, including patients seeking obesity surgery [37]. This misperception of expected therapeutic performance also extends to the HCP and may contribute to feelings of frustration of PwO. All of this suggests a lack of knowledge of the reality of obesity management, which can only be improved through personal education and professional training.

In Spain, according to $\mathrm{PwO}$, primary care physicians were the HCPs with whom weight was discussed most often, followed by nurses and endocrinologists. In the global dataset, after primary care physicians $(63 \%)$, dietitians/nutritionists (30\%) were the HCPs with whom weight was discussed most often (ACTION-IO study steering committee, personal communication). In Spain, HCPs perceived endocrinologists as the profession most effective in helping $\mathrm{PwO}$, unlike in the global dataset, in which the dietitian/nutritionist was perceived as most relevant (ACTION-IO study steering committee, personal communication). These differences reflect the characteristics of the Spanish healthcare system, which offers greater access to specialists than in other countries, but with limited access to nutritionists, who mainly work in Clinical Nutrition in a hospital setting.

Improvements in dietary habits and increased physical activity were considered to be the most effective methods for weight control by $\mathrm{PwO}$ and HCPs. Of note was the low recommendation of prescription weight loss medication, which was mainly perceived as having low efficacy by HCPs. The ACTION-IO study, extending to the results in Spain, reveals the great lack of knowledge on the efficacy of the therapeutic options by both $\mathrm{PwO}$ and HCPs. Only one-third of HCPs believe that there are good pharmacologic options available for weight loss, and 37\% acknowledge that they have insufficient knowledge of prescription weight loss medications. Both groups suggest that bariatric surgery is not an effective mid- or long-term treatment alternative, in stark contrast with current evidence [38]. It is therefore clear that in Spain there is a great need for education for $\mathrm{PwO}$ and training for HCPs in the evidence-based therapeutic management of obesity, which is a need that has been similarly identified globally [19].

Unlike in the global study, in which the internet was considered the primary source of information on all aspects related to the treatment of obesity (used by $40 \%$ of PwO; ACTION-IO study steering committee, personal communication), in Spain, PwO considered HCPs as their main source of information (used by $46 \%$ of $\mathrm{PwO}$ ), ranking higher than other sources such as social networks and television programs. These data emphasize the importance of addressing the shortcomings of HCPs that were revealed by the study, in terms of the recognition of their patients' motivation and objectives for weight loss and the therapeutic possibilities for this condition.

In general, the data on the Spanish population show no significant deviations from those found in the global ACTION-IO study [24]. The perception of obesity as a chronic disease, as well as the reasons for $\mathrm{PwO}$ not initiating a weight management dialogue with their $\mathrm{HCP}$, are reasonably comparable between the ACTION US [22] and ACTION Canada [23] studies and those obtained in the Spanish population in the ACTION-IO study. The ACTION-IO Spanish data regarding the delay in starting conversations between $\mathrm{PwO}$ and HCPs is also comparable with the data obtained in the global ACTION-IO [24] and ACTION Canada studies [23]. Additionally, the barriers to weight loss identified by the participating Spanish PwO and HCPs were similar to the global ACTION-IO cohort [24]. Variations dependent on heterogeneity in healthcare systems can likely be improved through the development of Obesity Units and both individual and group educational resources. Coordination between endocrinologists, the leading obesity specialty in Spain, primary care physicians, dietitians, and other specialists, independent of their public or private practice, is a key element that 
will help to break down the barriers detected in the ACTION-IO study for the Spanish population. There is a need to invest in efforts to improve $\mathrm{PwO}$ awareness and greater training for HCPs whose gaps/limitations have emerged as the common denominator of the discrepancies and obstacles observed in this study. Obesity treatment requires approaches aimed at the general population, $\mathrm{PwO}$, and $\mathrm{HCPs}$ in different areas, such as the family, school, social, or work environments, amongst others. With that in mind, it will be important for future studies to assess the perceptions, attitudes, and behaviors of a broader range of stakeholders such as nurses, dietitians, and adolescents with overweight or obesity.

The limitations of this research based on the results obtained in the Spanish population of the ACTION-IO study are identical to those of the global ACTION-IO study [24], including its cross-sectional design and the self-reported nature of the information provided by $\mathrm{PwO}$ and HCPs. PwO may underestimate their height and weight, which could impact on BMI estimations, and the results rely on the accuracy of the information declared retrospectively by the people surveyed. The use of the internet for the dissemination of the survey may also generate bias. Low response rates were expected and are typical of survey-based research. The proportion of Spanish HCPs who completed the survey was slightly lower, when compared with the global ACTION-IO study (6\% vs. $17 \%$ internationally [24]). A higher percentage of Spanish PwO completed the survey, when compared with the global study ( $24 \%$ vs. $20 \%$ internationally [24]). The strengths lie in the large number of participants, the scientific quality of the questions that form part of the survey, the screening criteria applied to participants, and the stratified sampling approach to provide a representative cohort of the general population.

\section{Conclusions}

Data from the Spanish sample of the ACTION-IO study indicate that there are significant discrepancies between perceptions, attitudes, motivation, and interactions between $\mathrm{PwO}$ and $\mathrm{HCPs}$ that translate into unrealistic goals for weight loss, a low rate of obesity diagnosis, and a low number of scheduled follow-ups, all of which have been identified as obstacles to effective obesity management.

Based on these results, it is essential to increase awareness, training, and education on obesity as key elements to improve therapeutic success, quality, and the life expectancy of PwO, and thus to decrease obesity complications and healthcare expenditure. Simultaneously, the possibility of optimizing the care strategy by generating models that facilitate $\mathrm{PwO}-\mathrm{HCP}$ interaction, a key element in the success of obesity treatment, should be evaluated.

Supplementary Materials: The following are available online at http://www.mdpi.com/2077-0383/9/9/2834/s1, Figure S1: Assessing the impact of health conditions on overall health, Figure S2: Reasons for not discussing weight with an HCP, Figure S3: Sources of information used by PwO for managing weight.

Author Contributions: Conceptualization, J.S.; methodology, J.S.; writing-original draft preparation, F.P., J.S., M.Á.R. and N.V.; writing-review and editing, F.P., J.S., M.Á.R. and N.V. All authors participated in interpretation of the data and drafting and revision of the manuscript. All authors have read and agreed to the published version of the manuscript.

Funding: This study was funded by Novo Nordisk.

Acknowledgments: We gratefully acknowledge the study participants and all personnel involved in the study. This study was sponsored by Novo Nordisk, which also provided financial support for medical editorial assistance from Bhavika Modasia PhD of Articulate Science, Ltd.

Conflicts of Interest: F.P. is an employee of Novo Nordisk. J.S., M.Á.R., and N.V. report personal fees for consultancy from Novo Nordisk, outside the submitted work. J.S. and N.V. report personal fees for travel expenses to attend author meetings from Novo Nordisk, during the conduct of the study. 


\section{References}

1. Lim, S.S.; Vos, T.; Flaxman, A.D.; Danaei, G.; Shibuya, K.; Adair-Rohani, H.; AlMazroa, M.A.; Amann, M.; Anderson, H.R.; Andrews, K.G.; et al. A comparative risk assessment of burden of disease and injury attributable to 67 risk factors and risk factor clusters in 21 regions, 1990-2010: A systematic analysis for the Global Burden of Disease Study 2010. Lancet 2012, 380, 2224-2260. [CrossRef]

2. Afshin, A.; Forouzanfar, M.H.; Reitsma, M.B.; Sur, P.; Estep, K.; Lee, A.; Marczak, L.; Mokdad, A.H.; Moradi-Lakeh, M.; Naghavi, M.; et al. Health effects of overweight and obesity in 195 countries over 25 years. N. Engl. J. Med. 2017, 377, 13-27. [CrossRef] [PubMed]

3. Ladeiras-Lopes, R.; Sampaio, F.; Bettencourt, N.; Fontes-Carvalho, R.; Ferreira, N.D.; Leite-Moreira, A.F.; Gama, V. The ratio between visceral and subcutaneous abdominal fat assessed by computed tomography is an independent predictor of mortality and cardiac events. Rev. Esp. Cardiol. 2017, 70, 331-337. [CrossRef] [PubMed]

4. Biener, A.I.; Decker, S.L. Agency for Healthcare Research and Quality. Medical care use and expenditures associated with adult obesity in the United States. JAMA 2018, 319, 218. [CrossRef]

5. Kassir, R. Risk of COVID-19 for patients with obesity. Obes. Rev. 2020, 21, e13034. [CrossRef]

6. Garg, S.; Kim, L.; Whitaker, M.; O’Halloran, A.; Cummings, C.; Holstein, R.; Prill, M.; Chai, S.J.; Kirley, P.D.; Alden, N.B.; et al. Hospitalization rates and characteristics of patients hospitalized with laboratory-confirmed coronavirus disease 2019-COVID-NET, 14 states, March 1-30, 2020. MMWR Morb. Mortal Wkly. Rep. 2020, 69, 458-464. [CrossRef]

7. Gutiérrez-Fisac, J.L.; Guallar-Castillón, P.; León-Muñoz, L.M.; Graciani, A.; Banegas, J.R.; Rodríguez-Artalejo, F. Prevalence of general and abdominal obesity in the adult population of Spain, 2008-2010: The ENRICA study. Obes. Rev. 2012, 13, 388-392. [CrossRef]

8. Organization for Economic Co-Operation and Development (OECD) Obesity Update 2017. Available online: https://www.oecd.org/els/health-systems/Obesity-Update-2017.pdf (accessed on 7 November 2019).

9. Hernáez, Á.; Zomeño, M.D.; Dégano, I.R.; Fernández, S.P.; Goday, A.; Vila, J.; Civeira, F.; Moure, R.; Marrugat, J. Excess weight in Spain: Current situation, projections for 2030, and estimated direct extra cost for the Spanish health system. Rev. Esp. Cardiol. 2019, 72, 916-924. [CrossRef]

10. Bray, G.A.; Kim, K.K.; Wilding, J.P.H. World Obesity Federation. Obesity: A chronic relapsing progressive disease process. A position statement of the World Obesity Federation. Obes. Rev. 2017, 18, 715-723. [CrossRef]

11. Ralston, J.; Brinsden, H.; Buse, K.; Candeias, V.; Caterson, I.; Hassell, T.; Kumanyika, S.; Nece, P.; Nishtar, S.; Patton, I.; et al. Time for a new obesity narrative. Lancet 2018, 392, 1384-1386. [CrossRef]

12. Ghanemi, A.; Yoshioka, M.; St-Amand, J. Broken energy homeostasis and obesity pathogenesis: The surrounding concepts. J. Clin. Med. 2018, 7, 453. [CrossRef] [PubMed]

13. Jensen, M.D.; Ryan, D.H.; Apovian, C.M.; Ard, J.D.; Comuzzie, A.G.; Donato, K.A.; Hu, F.B.; Hubbard, V.S.; Jakicic, J.M.; Kushner, R.F.; et al. 2013 AHA/ACC/TOS guideline for the management of overweight and obesity in adults: A report of the American College of Cardiology/American Heart Association Task Force on Practice Guidelines and The Obesity Society. Circulation 2014, 129 (Suppl. S2), S102-S138. [CrossRef] [PubMed]

14. Garvey, W.T.; Mechanick, J.I.; Brett, E.M.; Garber, A.J.; Hurley, D.L.; Jastreboff, A.M.; Nadolsky, K.; Pessah-Pollack, R.; Plodkowski, R. Reviewers of the AACE/ACE Obesity Clinical Practice Guidelines. American Association of Clinical Endocrinologists and American College of Endocrinology Comprehensive Clinical Practice Guidelines for Medical Care of Patients with Obesity. Endocr. Pract. 2016, 22 (Suppl. S3), 1-203. [CrossRef] [PubMed]

15. Schutz, D.D.; Busetto, L.; Dicker, D.; Farpour-Lambert, N.; Pryke, R.; Toplak, H.; Widmer, D.; Yumuk, V.; Schutz, Y. European practical and patient-centred guidelines for adult obesity management in primary care. Obes. Facts 2019, 12, 40-66. [CrossRef]

16. Glauser, T.A.; Roepke, N.; Stevenin, B.; Dubois, A.M.; Ahn, S.M. Physician knowledge about and perceptions of obesity management. Obes. Res. Clin. Pract. 2015, 9, 573-583. [CrossRef]

17. Turner, M.; Jannah, N.; Kahan, S.; Gallagher, C.; Dietz, W. Current knowledge of obesity treatment guidelines by health care professionals. Obesity 2018, 26, 665-671. [CrossRef] 
18. Puhl, R.M.; Heuer, C.A. Obesity stigma: Important considerations for public health. Am. J. Public Health 2010, 100, 1019-1028. [CrossRef]

19. Rubino, F.; Puhl, R.M.; Cummings, D.E.; Eckel, R.H.; Ryan, D.H.; Mechanick, J.I.; Nadglowski, J.; Salas, X.R.; Schauer, P.R.; Twenefour, D.; et al. Joint international consensus statement for ending stigma of obesity. Nat. Med. 2020, 26, 485-497. [CrossRef]

20. Apovian, C.M.; Aronne, L.; Rubino, D.; Still, C.; Wyatt, H.; Burns, C.; Kim, D.; Dunayevich, E.; Cor-II Study Group. A randomized, phase 3 trial of naltrexone SR/bupropion SR on weight and obesity-related risk factors (COR-II). Obesity 2013, 21, 935-943. [CrossRef]

21. Magallares, A.; Bolaños-Rios, P.; Ruiz-Prieto, I.; de Benito Valle, P.; Irles, J.A.; Jáuregui-Lobera, I. The mediational effect of weight self-stigma in the relationship between blatant and subtle discrimination and depression and anxiety. Span. J. Psychol. 2017, 20, E4. [CrossRef]

22. Kaplan, L.M.; Golden, A.; Jinnett, K.; Kolotkin, R.L.; Kyle, T.K.; Look, M.; Nadglowski, J.; O'Neil, P.M.; Parry, T.; Tomaszewski, K.J.; et al. Perceptions of barriers to effective obesity care: Results from the national ACTION study. Obesity 2018, 26, 61-69. [CrossRef]

23. Sharma, A.M.; Bélanger, A.; Carson, V.; Krah, J.; Langlois, M.; Lawlor, D.; Lepage, S.; Liu, A.; Macklin, D.A.; Mackay, N.; et al. Perceptions of barriers to effective obesity management in Canada: Results from the ACTION study. Clin. Obes. 2019, 9, e12329. [CrossRef] [PubMed]

24. Caterson, I.D.; Alfadda, A.; Auerbach, P.; Coutinho, W.; Cuevas, A.; Dicker, D.; Hughes, C.; Iwabu, M.; Kang, J.; Nawar, R.; et al. Gaps to bridge: Misalignment between perception, reality and actions in obesity. Diabetes Obes. Metab. 2019, 21, 1914-1924. [CrossRef] [PubMed]

25. International Society for Pharmacoepidemiology (ISPE). Guidelines for Good Pharmacoepidemiology Practices (GPP). Available online: https://www.pharmacoepi.org/resources/policies/guidelines-08027/ (accessed on 15 January 2020).

26. World Medical Association (WMA). World Medical Association Declaration of Helsinki: Ethical principles for medical research involving human subjects. JAMA 2013, 310, 2191-2194. [CrossRef] [PubMed]

27. Yumuk, V.; Tsigos, C.; Fried, M.; Schindler, K.; Busetto, L.; Micic, D.; Toplak, H. European Guidelines for Obesity Management in Adults. Obes. Facts 2015, 8, 402-424. [CrossRef]

28. Lecube, A.; Monereo, S.; Rubio, M.A.; Martínez-De-Icaya, P.; Marti, A.; Salvador, J.; Masmiquel, L.; Goday, A.; Bellido, D.; Lurbe, E.; et al. Prevention, diagnosis, and treatment of obesity. 2016 position statement of the Spanish Society for the Study of Obesity. Endocrinol. Diabetes Nutr. 2017, 64, 15-22. [CrossRef]

29. Mawardi, G.; Kirkland, E.B.; Zhang, J.; Blankinship, D.; Heincelman, M.E.; Schreiner, A.D.; Moran, W.P.; Schumann, S. Patient perception of obesity versus physician documentation of obesity: A quality improvement study. Clin. Obes. 2019, 9, e12303. [CrossRef]

30. Yaemsiri, S.; Slining, M.M.; Agarwal, S.K. Perceived weight status, overweight diagnosis, and weight control among US adults: The NHANES 2003-2008 study. Int. J. Obes. 2011, 35, 1063-1070. [CrossRef]

31. Whelton, P.K.; Carey, R.M.; Aronow, W.S.; Casey, N.E.; Collins, K.J.; Himmelfarb, C.R.D.; DePalma, S.M.; Gidding, S.; Jamerson, K.A.; Jones, D.W.; et al. 2017 ACC/AHA/AAPA/ABC/ACPM/AGS/APhA/ASH/ASPC/ NMA/PCNA Guideline for the Prevention, Detection, Evaluation, and Management of High Blood Pressure in Adults: A report of the American College of Cardiology/American Heart Association Task Force on Clinical Practice Guidelines. J. Am. Coll. Cardiol. 2018, 71, e127-e248. [CrossRef]

32. American Diabetes Association (ADA). Standards of Medical Care in Diabetes-2019 Abridged for Primary Care Providers. Clin. Diabetes 2019, 37, 11-34. [CrossRef]

33. Singh, S.; Somers, V.K.; Clark, M.M.; Vickers, K.; Hensrud, D.D.; Korenfeld, Y.; Lopez-Jimenez, F. Physician diagnosis of overweight status predicts attempted and successful weight loss in patients with cardiovascular disease and central obesity. Am. Heart J. 2010, 160, 934-942. [CrossRef] [PubMed]

34. Cole, A.M.; Keppel, G.A.; Andrilla, H.A. Primary care patients' willingness to participate in comprehensive weight loss programs: From the WWAMI Region Practice and Research Network. J. Am. Board Fam. Med. 2016, 29, 572-580. [CrossRef]

35. Ministerio de Sanidad, Servicios Sociales e Igualdad; Agencia Española de Consumo, Seguridad Alimentaria y Nutrición. Estudio Aladino 2015: Estudio de Vigilancia del Crecimiento, Alimentación, Actividad Física, Desarrollo Infantil y Obesidad en España 2015. Available online: http://www.aecosan.msssi.gob.es/ AECOSAN/web/nutricion/detalle/aladino_2015.htm (accessed on 7 January 2020). 
36. Willett, W.C.; Dietz, W.H.; Colditz, G.A. Guidelines for healthy weight. N. Engl. J. Med. 1999, 341, $427-434$. [CrossRef] [PubMed]

37. Dalle Grave, R.D.; Calugi, S.; Molinari, E.; Petroni, M.L.; Bondi, M.; Compare, A.; Marchesini, G. Weight loss expectations in obese patients and treatment attrition: An observational multicenter study. Obes. Res. 2005, 13, 1961-1969. [CrossRef] [PubMed]

38. Buchwald, H.; Avidor, Y.; Braunwald, E.; Jensen, M.D.; Pories, W.; Fahrbach, K.; Schoelles, K. Bariatric surgery: A systematic review and meta-analysis. JAMA 2004, 292, 1724-1737. [CrossRef] [PubMed]

(C) 2020 by the authors. Licensee MDPI, Basel, Switzerland. This article is an open access article distributed under the terms and conditions of the Creative Commons Attribution (CC BY) license (http://creativecommons.org/licenses/by/4.0/). 